\title{
Diagnostic Delay of Inflammatory Bowel Disease Is Significantly Higher in Public versus Private Health Care System in Mexican Patients
}

\author{
Jesús K. Yamamoto-Furusho ${ }^{a, b}$ Norma N. Parra-Holguín ${ }^{a}$ \\ anflammatory Bowel Disease Clinic, Department of Gastroenterology, National Institute of Medical Sciences and \\ Nutrition Salvador Zubirán, Mexico City, Mexico; ${ }^{b}$ Gastroenterology and Obesity Service, Médica Sur Hospital, \\ Mexico City, Mexico
}

\section{Keywords}

Delay · Diagnosis · Inflammatory bowel disease

\begin{abstract}
Introduction: Inflammatory bowel disease (IBD) includes ulcerative colitis (UC) and Crohn's disease (CD) characterized by a fluctuating course with periods of clinical activity and remission. No previous studies have demonstrated the frequency of delay at diagnosis and its associated factors in Mexico and Latin America. The aim of this study was to evaluate diagnostic delay of IBD in the last 4 decades in 2 different health care systems (public vs. private) and its associated factors. Methods: This is a cohort study that included 1,056 patients with a confirmed diagnosis of IBD from public and private health care systems. The diagnostic delay was defined as time $>1$ year from the onset of symptoms to the confirmed diagnosis for patients with UC and 2 years for patients with CD. Statistical analysis was performed with the SPSS v.24 program. A value of $p \leq 0.05$ was taken as significant. Results: The delay at diagnosis decreased significantly by $24.9 \%$ in the last 4 decades. The factors associated with the diagnostic delay were proctitis in UC, clinical course $>2$ relapses per year and IBD surgeries for $C D$. We found a delay
\end{abstract}

at diagnosis in $35.2 \%$ of IBD patients in the public versus $16.9 \%$ in the private health care system ( $p=0.00001)$. Conclusions: We found a significant diagnosis delay of IBD in $35.2 \%$ from the public health care system versus $16.9 \%$ in the private health care system.

(c) 2021 The Author(s).

Published by S. Karger AG, Basel

\section{Introduction}

Inflammatory bowel disease (IBD) includes ulcerative colitis (UC) and Crohn's disease (CD) characterized by a fluctuating course with periods of clinical activity and remission [1]. The incidence has increased in the last years in Mexico [2] and worldwide where approximately 6.8 million patients had been reported [3]. Diagnosis of IBD can be delayed due to the clinical heterogeneity and the differential diagnosis with other diseases. No established consensus or precise definition about delay diagnosis, however, previous studies have suggested that a period of time to confirmed diagnosis was 1-3 months for UC [4, 5], and 5-7 months for CD [4, 6]. Some factors have been related to the delay at diagnosis in some countries such as smoking, age at diagnosis $<60$ years, penetrating behavior

Correspondence to:

Jesús K. Yamamoto-Furusho, kazuofurusho@hotmail.com

karger@karger.com www.karger.com/iid

Karger $\stackrel{\text { ' }}{=}$

BOPEN ACCESS
(C) 2021 The Author(s)

Published by S. Karger AG, Basel

This is an Open Access article licensed under the Creative Commons Attribution-NonCommercial-4.0 International License (CC BY-NC) (http://www.karger.com/Services/OpenAccessLicense), applicable to the online version of the article only. Usage and distribution for commercial purposes requires written permission. 
of CD [7], and educational level [4]. This diagnostic delay in IBD may impact with greater complications like intestinal resections [8], stricture, perianal fistulas, and increased anti-tumor necrosis factor (TNF) alpha use [9]. A diagnostic delay can increase the costs of treatment due to complications and the need of hospitalizations [10], work productivity loss [11], and the use of new therapeutic agents [12]. For all these reasons, it is necessary to pay attention when IBD is suspected to reduce long-term complications and costs. Mexico has a public health program where coverage has increased in most of the country [13] and also has medical assistance through private coverage; the Mexican health system comprises 2 sectors, the public and the private. The public sector is composed of social security institutions that include people who work and their families and other where people have medical attention without access to social security and finally, the private sector includes insurance companies who work in private hospitals. The public health system includes $70.8 \%$ of the Mexican population and the rest 29.2\% require the services of the private health system [14]. For IBD, an increase in hospital discharges and mortality has been reported in the last years [15], for that reason a greater coverage of medical treatments is necessary for IBD. There are differences in the clinical outcomes depending on the health care system with higher mortality and complications in the public health system $[16,17]$ than the private health care system. In other countries, that have both health systems, it has been observed that patients with IBD with medical attention in the public health system have a higher percentage of diagnostic delay and late use of anti-TNF therapy resulting in an elevated number of hospitalizations [18]. We are aware that there is a diagnostic delay in IBD patients in Mexico; however, there are important advances in the diagnostic tools and awareness of IBD in the last decade in our country. For this reason, the aim of this study was to evaluate if there is a decrease in the diagnostic delay of IBD in the last 4 decades and its associated factors of the clinical differences between 2 reference centers of different kinds of health care systems (public vs. private) in Mexico.

\section{Material and Methods}

This is a cohort study that included all patients with a confirmed diagnosis of IBD, based on clinical, endoscopic, radiologi$\mathrm{cal}$, and histological findings. All patients belonged to the IBD Clinic at the National Institute of Medical Sciences and Nutrition Salvador Zubirán from the public health care system and the Gastroenterology Service in Medica Sur, a hospital from the private

Diagnostic Delay of Inflammatory Bowel

Disease in Mexico health care system. In this study, both public and private hospitals are the main reference medical centers that admit patients with IBD in whole country. There is no switching from public and private system. All patients who started symptoms of the disease in the period 1980-2019 with complete medical records were included.

All clinical and demographic variables were collected from a hospital-based data by reviewing clinical records and by personal interview of variables such as sex; age, age at the onset of symptoms (chronic diarrhea, abdominal pain, bloody stools, body weight loss, fever, tenesmus, and anemia or extraintestinal symptoms that are attributed to IBD), age at diagnosis, year of diagnosis, disease duration, type of IBD diagnosis, public or private health care systems, the extent of UC, location in $\mathrm{CD}$, clinical behavior of $\mathrm{CD}$, clinical course of disease, family history of IBD or immune-mediated diseases, extraintestinal manifestations, smoking habit, steroid-dependent, resistant to steroids, refractory to thiopurines, anti-TNF primary nonresponder, secondary loss of response to anti-TNF alpha, previous number of hospitalizations, and relapse were defined in those patients who have clinical symptoms such diarrhea, bloody stools, abdominal pain, etc., and had reached clinical remission for at least 3 months, current medical therapy with 5-aminosalicylates (5-ASA), steroids, immunomodulators, and biological therapy, as well as IBD surgical treatment. Diagnostic delay was defined as a period of time $>1$ year from the onset of symptoms to the confirmed diagnosis for patients with UC and 2 years for CD [18].

\section{Statistics Analysis}

For the description of the demographic and clinical characteristics, frequencies, and percentages will be used for categorical variables and median and range for continuous variables. $\chi^{2}$ was used for categorical variables and the Student's t test to compare number variables. A univariate and multivariate analysis were performed to identify all factors associated with diagnostic delay. Statistical analysis was performed with the SPSS v.24 program. A value of $p \leq 0.05$ was considered as significant.

\section{Results}

\section{Clinical and Demographic Characteristics}

A total of 1,056 patients with IBD consisted of 843 patients with UC which 275 had diagnostic delay and 568 with nondiagnostic delay as well as 213 patients with CD, 42 had diagnostic delay and 171 with nondiagnostic delay. The most frequent clinical characteristics associated with diagnostic delay were diarrhea and abdominal pain in CD and UC as shown in Table 1. The presence of anal lesions was not associated with diagnostic delay.

\section{Time to Confirmed Diagnosis of IBD}

All patients were classified according to the decade, at the time when they started with IBD symptoms, time to diagnosis, diagnostic or nondiagnostic delay. We found an increased in timely diagnosis from $55.2 \%$ in 1980 
Table 1. Clinical and demographic characteristics

\begin{tabular}{|c|c|c|c|c|}
\hline & $\begin{array}{l}\text { UC delay } \\
n=275\end{array}$ & $\begin{array}{l}\text { UC nondelay } \\
n=568\end{array}$ & $\begin{array}{l}\text { CD delay } \\
n=42\end{array}$ & $\begin{array}{l}\text { CD nondelay } \\
n=171\end{array}$ \\
\hline \multicolumn{5}{|l|}{ Sex, $n(\%)$} \\
\hline Female & $159(57.8)$ & $285(50.2)$ & $26(54.8)$ & $90(52.6)$ \\
\hline Male & $116(42.2)$ & $283(49.8)$ & $19(45.2)$ & $81(47.4)$ \\
\hline Median age (range) & $43(17-79)$ & $40(8-89)$ & $53(25-82)$ & $50(13-98)$ \\
\hline Median years of evolution (range) & $8(1-37)$ & $6(1-41)$ & $8(2-32)$ & $5(1-37)$ \\
\hline \multicolumn{5}{|l|}{ Family history, $n(\%)$} \\
\hline $\mathrm{IBD}$ & $6(2.2)$ & $10(1.8)$ & $1(2.4)$ & $2(1.2)$ \\
\hline Immune-mediated disease & $28(10.2)$ & $29(5.1)$ & $1(2.4)$ & $9(5.3)$ \\
\hline Smoking, $n(\%)$ & $98(35.6)$ & $181(31.9)$ & $19(45.2)$ & $50(29.2)$ \\
\hline Extraintestinal manifestations, $n$ (\%) & $92(33.5)$ & $140(24.6)$ & $13(31.0)$ & $41(24.0)$ \\
\hline \multicolumn{5}{|l|}{ Symptoms, $n(\%)$} \\
\hline Diarrhea & $265(96.3)^{*}$ & $450(79.2)$ & $40(95.2)^{*}$ & $145(84.7)$ \\
\hline Abdominal pain & $255(92.7)^{*}$ & $310(54.5)$ & $41(97.6)^{*}$ & $136(79.5)$ \\
\hline Bloody stools & $275(100)$ & $568(100)$ & $31(73.8)$ & $125(73)$ \\
\hline Weight loss & $268(97.4)$ & $555(97.7)$ & $40(95.2)$ & $165(96.4)$ \\
\hline Fever & $100(36.3)$ & $215(37.8)$ & $18(42.8)$ & $91(53.2)$ \\
\hline Anemia & $275(100)$ & $568(100)$ & $42(100)$ & $171(100)$ \\
\hline Clinical remission, $n$ (\%) & $150(54.5)$ & $288(50.7)$ & $19(45.2)$ & $90(52.6)$ \\
\hline \multicolumn{5}{|l|}{ Extent of UC, $n(\%)$} \\
\hline E1 proctitis & $23(8.4)$ & $130(22.9)$ & & \\
\hline E2 left-sided & $33(12.0)$ & $75(13.2)$ & & \\
\hline E3 extensive & $219(79.6)$ & $363(63.9)$ & & \\
\hline \multicolumn{5}{|l|}{ Location of CD, $n(\%)$} \\
\hline Ileal & & & $23(54.8)$ & $57(33.3)$ \\
\hline Colonic & & & $6(14.3)$ & $37(21.6)$ \\
\hline Ileocolonic & & & $12(28.6)$ & $65(38.0)$ \\
\hline Upper disease & & & $1(2.4)$ & $5(2.9)$ \\
\hline Perianal disease & & & 0 & $7(4.1)$ \\
\hline \multicolumn{5}{|l|}{ Behavior CD, $n(\%)$} \\
\hline Penetrating & & & $15(35.7)$ & $93(54.4)$ \\
\hline Stricturing & & & $21(50.0)$ & $56(32.7)$ \\
\hline Penetrating & & & $6(14.3)$ & $22(12.9)$ \\
\hline \multicolumn{5}{|l|}{ Clinical course, $n(\%)$} \\
\hline Initially active and prolonged remission & $196(71.3)$ & $355(62.5)$ & $26(61.9)$ & $112(65.5)$ \\
\hline$<2$ relapses per year & $71(25.8)$ & $179(31.5)$ & $11(26.2)$ & $57(33.3)$ \\
\hline$>2$ relapses per year & $8(2.9)$ & $34(6.0)$ & $5(11.9)$ & $2(1.2)$ \\
\hline IBD surgeries & $14(5.1)$ & $31(5.5)$ & $16(38.1)$ & $33(19.3)$ \\
\hline \multicolumn{5}{|l|}{ Previous hospitalizations, $n$ (\%) } \\
\hline$<2$ & $1,187(68.0)$ & $387(68.1)$ & $19(45.2)$ & $102(59.6)$ \\
\hline$>2$ & $88(32)$ & $181(31.9)$ & $23(54.8)$ & $69(40.4)$ \\
\hline
\end{tabular}

UC, ulcerative colitis; $n$, number of patients; CD, Crohn's disease; IBD, inflammatory bowel disease. ${ }^{*} p<0.05$.

1989 to $81.1 \%$ for $2010-2019$, when they were classified by type of IBD, in the decade of 1980-1989 of patients with UC, $47.6 \%$ presented a timely diagnosis versus $52.4 \%$ with a diagnostic delay $(p=0.06)$; in the period of 1990 1999 was $46.8 \%$ versus $53.2 \%(p=0.0012)$; in the period of $2000-2009$ was $60.1 \%$ versus $39.9 \%(p=0.0007)$ and for $2010-2019$ was $78.1 \%$ versus $21.9 \%$ ( $p=0.00001)$. For CD in $1980-1989,75.0 \%$ with timely diagnosis versus
$25.0 \%$ with diagnostic delay $(p=0.65)$; in $1990-1999$ was $68.8 \%$ versus $31.3 \%(p=0.22)$; in $2000-2009$ was $63.2 \%$ versus $36.8(p=0.0007)$; and in the period 2010-2019 was $92.2 \%$ versus $7.8 \%(p=0.0017)$.

\section{Factors Associated with Diagnostic Delay}

A multivariate analysis was performed to search all factors associated with diagnostic delay. In the case of 
Table 2. Factors associated with diagnostic delay of IBD

\begin{tabular}{|c|c|c|c|c|c|}
\hline & \multicolumn{3}{|c|}{ Univariate analysis } & \multicolumn{2}{|c|}{ Multivariate analysis } \\
\hline & $p$ value & OR & $95 \% \mathrm{Cl}$ & $p$ value & OR \\
\hline \multicolumn{6}{|l|}{ UC } \\
\hline \multicolumn{6}{|l|}{ Family history } \\
\hline Immune-mediated disease & 0.008 & 2.1 & $1.22-3.61$ & 0.036 & 0.557 \\
\hline Extraintestinal manifestations & $<0.0013$ & 0.45 & $0.32-0.65$ & 0.166 & 1.484 \\
\hline Proctitis & $<0.0011$ & 0.30 & $0.19-0.49$ & 0.000 & 3.019 \\
\hline Arthralgias & 0.03 & 1.44 & $1.02-2.04$ & 0.940 & 0.165 \\
\hline \multicolumn{6}{|l|}{$C D$} \\
\hline \multicolumn{6}{|l|}{ Clinical course } \\
\hline$>2$ relapses per year & 0.02 & 6.09 & $1.30-28.36$ & 0.004 & 0.82 \\
\hline IBD surgeries & 0.013 & 2.57 & $1.24-5.33$ & 0.004 & 3.050 \\
\hline
\end{tabular}

$\mathrm{IBD}$, inflammatory bowel disease; $\mathrm{OR}$, odds ratio; $\mathrm{Cl}$, confidence interval; UC, ulcerative colitis; $\mathrm{CD}, \mathrm{Crohn}$ 's disease.

Fig. 1. Diagnostic delay by public or private health care system. IBD, inflammatory bowel disease; UC, ulcerative colitis; CD, Crohn's disease.

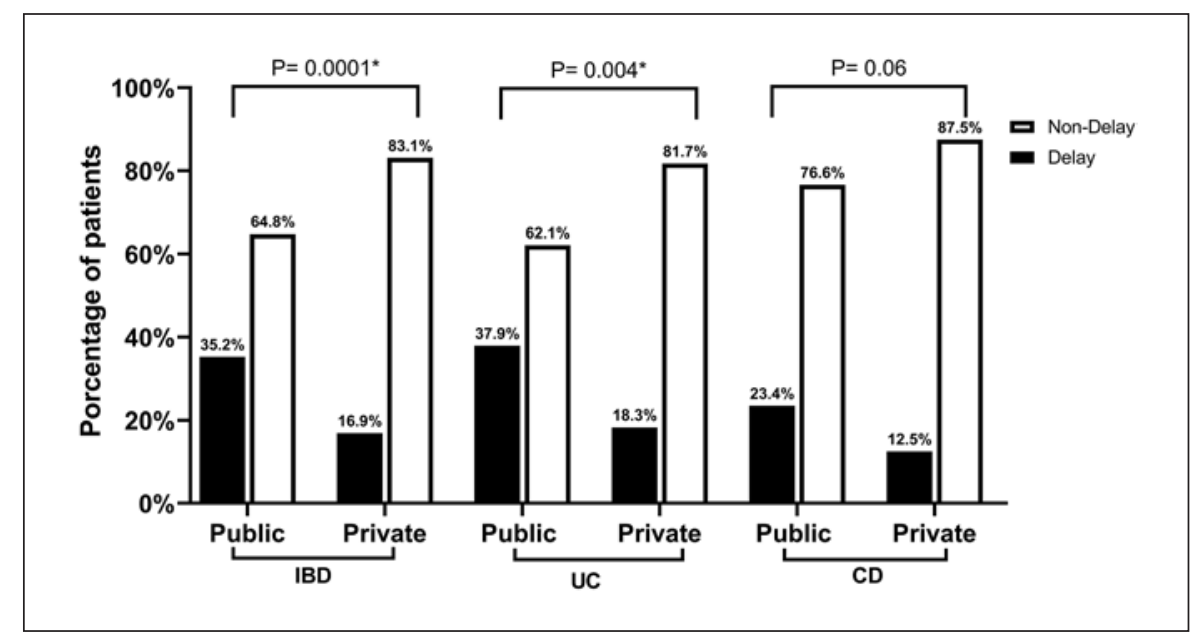

UC, all significant variables were family history of immune-mediated disease, abdominal pain, diarrhea, extraintestinal manifestations, proctitis, and arthralgias. The multivariate analysis found that proctitis persisted as an associated factor. In CD, the clinical course $>2$ relapses per year and IBD-related surgeries remained significant in the multivariate analysis as shown in Table 2.

\section{Differences in Diagnostic Delay by Public or Private \\ Health Care System}

A total of 755 patients with IBD who belonged to the public health care system were 614 (81.3\%) with a diagnosis of UC and 141 (18.7\%) with CD. From the private health care system, 301 patients were included, 229 (76.1\%) with a diagnosis of UC and 72 (23.9\%) with diagnosis of CD. The presence of diagnostic delay versus non-

Diagnostic Delay of Inflammatory Bowel Disease in Mexico diagnostic delay in both health care systems, we found a delay in 266 patients $(35.2 \%)$ in the public health care system versus 51 patients $(16.9 \%)$ in the private health care system ( $p=0.00001$, odds ratio [OR] 2.66, confidence interval [CI] 95\%: 1.90-3.73). There is a diagnostic delay of $37.9 \%$ versus $18.3 \%$ for UC ( $p=0.0004$, OR 2.27 , CI 95\% 1.87-3.95) and for CD a diagnostic delay of $23.4 \%$ versus $12.5 \%$ respectively ( $p=0.06$, OR 2.13 , CI $95 \%$ : $0.96-4.75)$ as shown in Figure 1.

\section{Clinical Differences in the Public and Private Health Care Systems}

A sub-analysis was carried out based on the clinical characteristics (Table 3 ) of the patients in public and private health care systems to find all factors associated with a diagnostic delay in each health care system. The only 


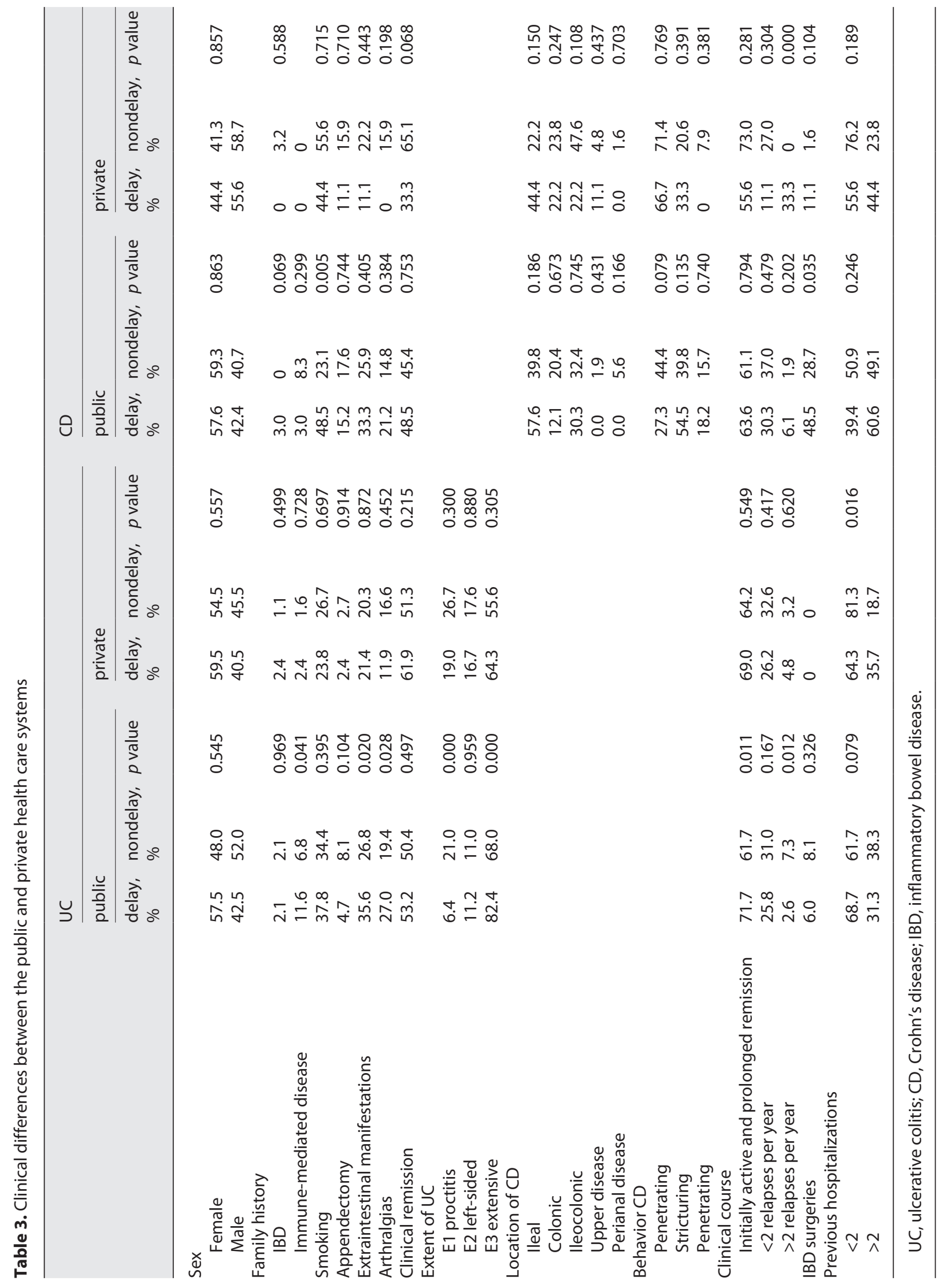


Table 4. Clinical differences of public and private health care patients

\begin{tabular}{|c|c|c|c|c|c|}
\hline & \multicolumn{3}{|c|}{ Univariate analysis } & \multicolumn{2}{|c|}{ Multivariate analysis } \\
\hline & $p$ value & OR & $\mathrm{Cl} 95 \%$ & $p$ value & OR \\
\hline \multicolumn{6}{|l|}{ UC public } \\
\hline \multicolumn{6}{|l|}{ Family history } \\
\hline Immune-mediated disease & 0.03 & 1.78 & $1.01-3.14$ & 0.196 & 0.682 \\
\hline Extraintestinal manifestations & 0.01 & 1.51 & $1.06-2.15$ & 0.650 & 1.156 \\
\hline Arthalgias & 0.01 & 1.53 & $1.04-2.25$ & 0.490 & 0.798 \\
\hline Pancolitis & 0.0004 & 2.2 & $1.47-3.29$ & 0.667 & 1.124 \\
\hline Proctitis & 0.0005 & 0.25 & $0.14-0.46$ & $0.001 *$ & 0.298 \\
\hline \multicolumn{6}{|l|}{ Clinical course } \\
\hline Initially active and prolonged remission & 0.007 & 1.57 & $1.10-2.23$ & 0.061 & 1.436 \\
\hline \multicolumn{6}{|l|}{ Clinical course } \\
\hline$>2$ relapses per year & 0.007 & 3.0 & $1.22-7.36$ & 0.342 & 0.285 \\
\hline \multicolumn{6}{|l|}{ UC private } \\
\hline \multicolumn{6}{|l|}{ Previous hospitalizations } \\
\hline$<2$ & 0.01 & 0.41 & $0.19-0.86$ & $0.018 *$ & 2.413 \\
\hline \multicolumn{6}{|l|}{ CD public } \\
\hline Smoking & 0.005 & 3.12 & $1.38-7.06$ & $0.018 *$ & 0.364 \\
\hline IBD surgeries & 0.03 & 2.33 & $1.05-5.20$ & 0.117 & 1.942 \\
\hline \multicolumn{6}{|l|}{ CD private } \\
\hline \multicolumn{6}{|l|}{ Clinical course } \\
\hline$>2$ relapses per year & 0.001 & 36.57 & $3.57-374.42$ & 0.999 & 0 \\
\hline
\end{tabular}

OR, odds ratio; $\mathrm{Cl}$, confidence interval; UC, ulcerative colitis; IBD, inflammatory bowel disease; $C D, C$ rohn's disease. ${ }^{*} p<0.05$.

Table 5. Treatment differences between public and private health care systems

\begin{tabular}{|c|c|c|c|c|c|c|c|c|c|}
\hline \multirow[t]{2}{*}{ Treatment } & \multicolumn{3}{|l|}{ UC } & \multicolumn{3}{|l|}{$C D$} & \multirow{2}{*}{$\begin{array}{l}\text { Public } \\
n=755\end{array}$} & \multirow{2}{*}{$\begin{array}{l}\text { Private } \\
n=301\end{array}$} & \multirow[t]{2}{*}{$p$ value } \\
\hline & $\begin{array}{l}\text { delay } \\
n=275\end{array}$ & $\begin{array}{l}\text { nondelay } \\
n=568\end{array}$ & $p$ value & $\begin{array}{l}\text { delay } \\
n=42\end{array}$ & $\begin{array}{l}\text { nondelay } \\
n=171\end{array}$ & $p$ value & & & \\
\hline 5-ASA & 72.4 & 76.4 & 0.203 & 35.7 & 39.2 & 0.679 & 64.5 & 75.7 & $0.0004^{*}$ \\
\hline Steroids & 14.5 & 68.3 & 820 & 23.8 & 32.7 & 0.262 & 16.8 & 21.6 & 0.069 \\
\hline Immunomodulators & 33.2 & 22.4 & 0.858 & 61.9 & 41.5 & $0.017 *$ & 26.4 & 29.2 & 0.343 \\
\hline Biologic treatment & 6.2 & 6.0 & 0.911 & 7.1 & 5.2 & 0.172 & 6.4 & 10.6 & $0.02 *$ \\
\hline
\end{tabular}

UC, ulcerative colitis; CD, Crohn's disease; $n$, number of patients; 5-ASA, 5-aminosalycilates. ${ }^{*} p<0.05$.

factor associated was proctitis ( $p=0.001$, OR 0.298$)$ in UC patients from the public health care system, and in the private health care system, the only associated factor was $<2$ hospitalizations ( $p=0.018$ OR 2.413 ) in UC. In patients with $\mathrm{CD}$ from the public health care system, the presence of smoking was significantly less in those who had timely diagnosis compared to CD patients with diagnostic delay ( $p=0.018$ OR 0.364 ). No differences were found in this issue for $\mathrm{CD}$ patients from the private health care system as shown in Table 4.

Diagnostic Delay of Inflammatory Bowel Disease in Mexico
Treatment Differences between Public and Private

Health Care Systems

The current medical treatment in patients with diagnostic delay and nondiagnostic delay, the only difference was higher use of immunomodulators in patients with $\mathrm{CD}(p=0.017)$ for diagnostic delay. Both public and private health care systems showed differences in higher use of 5-ASA $(p=0.0004)$ and anti-TNF alpha biological treatment $(p=0.02)$ in the private health care system as shown in Table 5. 
Complications between Diagnostic Delay and

Nondelay Diagnostic of IBD

The presence of complications in the long-term was significantly higher in those patients with $\mathrm{CD}$ delay diagnosis ( $50 \%$ vs. $0 \%$, respectively, $p<0.001$ ) regarding the development of strictures (40\%), surgical resections (35\%), intestinal perforation (12\%) and intra-abdominal abscess (5\%) as well as in UC patients with diagnostic delay had more complications than nondiagnostic delay $(15 \%$ vs. $0 \%$ respectively, $p<0.03)$ and the complications most frequent were toxic megacolon (7\%), colon perforation $(6 \%)$, refractory bleeding (1\%), colorectal cancer $(1 \%)$, and the need of colectomy $(15 \%)$.

\section{Discussion}

This is the first study from Latin American country that evaluates the diagnostic delay in IBD patients and compares 2 health care systems (public and private). We standardized the time to consider their diagnostic delay based on previous studies, where they showed that diagnostic delay is longer for CD than UC patients [19-21]. The diagnostic delay improved in recent years as demonstrated in our study where diagnostic delay decreased substantially in $24.9 \%$ in the last 4 decades. For the decade 2010-2019, the delay in the diagnosis of IBD was $18.9 \%$, similar to other populations from France and Romania $[6,20]$. This frequency is higher than other countries such as USA where diagnoses from the onset of symptoms in patients with CD is 10 months and 3 months for patients with UC, $<1$ year for both diseases [21]. This can be reflected in a lower frequency of IBD surgeries than other countries [22], thus avoiding the complications associated with a diagnostic delay such as stricturing phenotype and IBD-related surgeries [21, 23]. Also, the benefits of a timely diagnosis have been demonstrated in a higher quality of life throughout the clinical course of the disease than patients with a diagnostic delay [24]. The timely diagnosis in UC was $78.1 \%$ and for CD of $92.2 \%$ in the last decade as reported in other countries [19]. This finding may be due to a higher incidence of IBD worldwide and better knowledge, awareness of IBD in the gastroenterologists and new diagnostic tools such as fecal calprotectin, better endoscopic procedures and cross-imaging studies. Few factors were associated with a diagnostic delay such as proctitis in UC and CD-related surgeries. Interestingly a clinical course $>2$ relapses per year in $\mathrm{CD}$ was associated with a timely diagnosis. The potential explanation about proctitis was involved in the diagnostic delay of UC is that most of the patients were treated as other anal diseases such as hemorrhoids. On the other hand, IBD-related surgeries were a factor associated with diagnostic delay because most of the CD patients had a major complication due to the development of intestinal occlusion or penetrating behavior with intra-abdominal abscess formation and intestinal perforation. The presence of $>2$ relapses per year was associated with a timely diagnosis because CD patients looked for medical attention in a short time. No association was found with other clinical factors as reported previously, such as smoking [20], age at diagnosis $<40$ years and ileal location in CD [19], and no family history of IBD [25]. There was a higher frequency of diagnostic delay in the public than the private health care system because there was a long period for referring to the gastroenterologist or IBD specialist due to a bigger number of patients in the public health care system. Other differences found between both health care systems were a higher use of 5-ASA and anti-TNF alpha biological therapy in the private health care system, which may be explained by faster medical attention [26]. This finding is according to a previous study that confirmed a substantial benefit with the early use of these therapies [27]. When we compared both health care systems, the presence of proctitis was confirmed as a factor associated with a diagnostic delay in the public health care system contrasting to the lower number of hospitalizations of UC patients in the private health care system. In the case of CD patients in the public health care system, the smoking habit was associated with timely diagnosis, this can be explained because all patients had an aggressive clinical course and diagnostic studies were performed in a short period of time due to a hospitalization approach. Finally, it is important to mention that endemic gastrointestinal infections may be influencing on diagnostic delay in Mexico because it has been reported a high frequency of protozoa infections in Mexican patients with UC [28] as well as endemic tuberculosis may be influencing diagnostic delay of $\mathrm{CD}$ in a previous study from India [29].

The main advantage is that it is the first study to be carried out in Latin America for the diagnostic delay and compared 2 different health care systems (public vs. private) as well as we also looked for the factors associated. A limitation of the present study is that culture, education, socioeconomic status, and ethnicity were not explored, however, definitively these factors may be influencing on diagnostic delay in Mexican IBD patients.
78

Inflamm Intest Dis 2022;7:72-80 DOI: $10.1159 / 000520522$
Yamamoto-Furusho/Parra-Holguín 


\section{Conclusions}

We found a significant diagnostic delay of IBD in $35.2 \%$ from the public health care system versus $16.9 \%$ in the private health care system. These differences also remain statistically significant in UC ( $37.9 \%$ vs. $18.3 \%)$ and $23.4 \%$ versus $12.5 \%$, respectively for $\mathrm{CD}$. The factors associated with diagnostic delay were proctitis in UC patients, clinical course $>2$ relapses per year, and IBD-related surgeries were associated in CD patients.

\section{Statement of Ethics}

This work was performed according to the principles of the Declaration of Helsinki, 1989. The study was approved by the ethical and research committee of the National Institute of Medical Sciences and Nutrition (Ref. 2309) and written informed consent was obtained from all patients.

\section{Conflict of Interest Statement}

The authors have no conflicts of interest to declare.

\section{Funding Sources}

This research has no funding.

\section{Author Contributions}

J.K.Y.-F. contributed to conceptualization, J.K.Y.-F. and N.N.P.-H. contributed to data curation., J.K.Y.-F. and N.N.P.-H. contributed to formal analysis, J.K.Y.-F. contributed to funding acquisition, J.K.Y.-F. and N.N.P.-H. contributed to investigation, J.K.Y.-F. and N.N.P.-H. contributed to methodology, J.K.Y.-F. contributed to project administration, J.K.Y.-F. provided the resources., J.K.Y.-F. and N.N.P.-H. worked on software., J.K.Y.-F. contributed to supervision, J.K.Y.-F. contributed to validation, J.K.Y.-F. and N.N.P.-H. contributed to visualization, J.K.Y.-F. and N.N.P.-H. contributed to writing original draft, and J.K.Y.-F. contributed to writing review and editing.

\section{Data Availability Statement}

All data generated during this study are included in this article.

\section{References}

1 Gecse KB, Vermeire S. Differential diagnosis of inflammatory bowel disease: imitations and complications. Lancet Gastroenterol Hepatol. 2018;3:644-53.

2 Yamamoto Furusho JK, Sarmiento-Aguilar A, Toledo-Mauriño JJ, Bozada-Gutiérrez K, Bosques-Padilla FJ, Martínez-Vázquez M, et al. Incidence and prevalence of inflammatory bowel disease in Mexico from a nationwide cohort study in a period of 15 years (20002017). Medicine. 2019;98:e16291.

3 GBD 2017 Inflammatory Bowel Disease Collaborators. The global, regional, and national burden of inflammatory bowel disease in 195 countries and territories, 1990-2017: a systematic analysis for the Global Burden of Disease Study 2017. Lancet Gastroenterol Hepatol. 2019:5:17-30.

4 Novacek G, Gröchenig HP, Haas T, Wenzl H, Steiner P, Koch R, et al. Diagnostic delay in patients with inflammatory bowel disease in Austria. Wien Klin Wochenschr. 2019;131:104-12.

5 Cantoro L, Di Sabatino A, Papi C, Margagnoni G, Ardizzone S, Giuffrida P, et al. The time course of diagnostic delay in inflammatory bowel disease over the last sixty years: an Italian multicentre study. J Crohns Colitis. 2017; 11:975-80.
6 Nahon S, Lahmek P, Lesgourgues B, Poupardin C, Chaussade S, Peyrin-Biroulet L, et al. Diagnostic delay in a French cohort of Crohn's disease patients. J Crohns Colitis. 2014;8:964-9.

7 Moon CM, Jung SA, Kim SE, Song HJ, Jung $\mathrm{Y}$, Ye BD, et al. Clinical factors and disease course related to diagnostic delay in Korean Crohn's disease patients: results from the CONNECT Study. PLoS One. 2015; 10: e0144390.

8 Lee DW, Koo JS, Choe JW, Suh SJ, Kim SY, Hyun JJ, et al. Diagnostic delay in inflammatory bowel disease increases the risk of intestinal surgery. World J Gastroenterol. 2017;23: 6474-81.

9 Kang HS, Koo JS, Lee KM, Kim DB, Lee JM, Kim YJ, et al. Two-year delay in ulcerative colitis diagnosis is associated with anti-tumor necrosis factor alpha use. World J Gastroenterol. 2019;25:989-1001.

10 Rodríguez-Lago I, Zabana Y, Barreiro-de Acosta M. Diagnosis and natural history of preclinical and early inflammatory bowel disease. Ann Gastroenterol. 2020;33:443-52.

11 Park KT, Ehrlich OG, Allen JI, Meadows P, Szigethy EM, Henrichsen K, et al. The cost of inflammatory bowel disease: an initiative from the Crohn's \& Colitis Foundation. Inflamm Bowel Dis. 2020;26:1-10.
12 Pillai N, Dusheiko M, Maillard MH, Rogler G Brüngger B, Bähler $\mathrm{C}$, et al. The evolution of health care utilisation and costs for inflammatory bowel disease over ten years. J Crohns Colitis. 2019;13:744-54.

13 Grogger J, Arnold T, León AS, Ome A. Heterogeneity in the effect of public health insurance on catastrophic out-of-pocket health expenditures: the case of Mexico. Health Policy Plan. 2014;30:593-9.

14 Gómez-Dantés O, Sesma S, Becerril VM, Knaul FM, Arreola H, Frenk J. Sistema de salud de México. Salud Pública de Mexico. 2011;53(Suppl 2):S220-32.

15 Yamamoto-Furusho JK, Bosques-Padilla FJ, Charúa-Guindic L, Cortés-Espinosa T, Miranda-Cordero RM, Saez A, et al. Inflammatory bowel disease in México: epidemiology, burden of disease and treatment trends. Rev Gastroenterol México. 2020;85:246-56.

16 Ruiz-Sandoval JL, Briseño-Godínez ME, Chiquete-Anaya E, Arauz-Góngora A, TroyoSanromán R, Parada-Garza JD, et al. Public and private hospital care disparities of ischemic stroke in Mexico: results from the Primer Registro Mexicano de Isquemia Cerebral (PREMIER) Study. J Stroke Cerebrovasc Dis. 2018;27:445-53. 
17 Sarmiento-Aguilar A, Ríos-Blancas MJ, Yamamoto-Furusho JK. Mortality and hospitalizations in Mexican patients with inflammatory bowel disease: results from a nationwide. Can J Gastroenterol Hepatol. 2020:8825330.

18 Rumman A, Candia R, Sam JJ, Croitoru K, Silverberg MS, Steinhart AH, et al. Public versus private drug insurance and outcomes of patients requiring biologic therapies for inflammatory bowel disease. Can J Gastroenterol Hepatol. 2017;2017:7365937.

19 Vavricka SR, Spigaglia SM, Rogler G, Pittet V, Michetti P, Felley C, et al. Systematic evaluation of risk factors for diagnostic delay in inflammatory bowel disease. Inflamm Bowel Dis. 2012;18:496-505.

20 Zaharie R, Tantau A, Zaharie F, Tantau M, Gheorghe L, Gheorghe C, et al. Diagnostic delay in Romanian patients with inflammatory bowel disease : risk factors and impact on the disease course and need for surgery. J Crohns Colitis. 2016;10:306-14.

21 Nguyen VQ, Jiang D, Hoffman SN, Guntaka S, Mays JL, Wang A, et al. Impact of diagnostic delay and associated factors on clinical outcomes in a U.S. inflammatory bowel disease cohort. Inflamm Bowel Dis. 2017;23:1825-31.
22 Yamamoto-Furusho JK, Parra-Holguín NN, Grupo-Colombiano E, Bosques-Padilla F, Veitia-Velásquezet G, Torres E, et al. P749 epidemiological and clinical characterisation of inflammatory bowel disease (IBD) in Latin America and the Caribbean: the EPI-LATAM IBD study from the Pan American Crohn's colitis organisation. J Crohns Colitis. 2020;14: S599-600.

23 Safroneeva E, Vavricka SR, Fournier N, Pittet V, Peyrin-Biroulet L, Straumann A, et al. Impact of the early use of immunomodulators or TNF antagonists on bowel damage and surgery in Crohn's disease. Aliment Pharmacol Ther. 2015;42:977-89.

24 Pellino G, Sciaudone G, Selvaggi F, Riegler G. Delayed diagnosis is influenced by the clinical pattern of Crohn's disease and affects treatment outcomes and quality of life in the long term: a cross-sectional study of 361 patients in Southern Italy. Eur J Gastroenterol Hepatol. 2015;27:175-81.

25 Li Y, Ren J, Wang G, Gu G, Wu X, Ren H, et al. Diagnostic delay in Crohn's disease is associated with increased rate of abdominal surgery: a retrospective study in Chinese patients. Dig Liver Dis. 2015;47:544-8.
26 Grob L, Bluemel S, Biedermann L, Fournier N, Rossel JB, Vavricka SR, et al. Effect of distance to specialist care for the diagnosis and disease outcome of inflammatory bowel disease in the Swiss inflammatory bowel disease cohort study. Therap Adv Gastroenterol. 2020;13:1756284819895217.

27 D'Haen G, Baert F, van Assche G, Caenepeel $\mathrm{P}$, Vergauwe P, Tuynman H, et al. Early combined immunosuppression or conventional management in patients with newly diagnosed Crohn's disease: an open randomised trial. Lancet. 2008;371:660-7.

28 Yamamoto-Furusho JK, Torijano-Carrera E. Intestinal protozoa infections among patients with ulcerative colitis: prevalence and impact on clinical disease course. Digestion. 2010;82: 18-23.

29 Banerjee R, Pal P, Girish BG, Reddy DN. Risk factors for diagnostic delay in Crohn's disease and their impact on long-term complications: how do they differ in a tuberculosis endemic region? Aliment Pharmacol Ther. 2018;47: 1367-74. 